\title{
Depression: Like a Common Cold of Human Beings
}

Our mood varies according to events in the world around us. We are saddened (depressed) when we fail to reach in goal or lose a test. Similarly we are happy or enjoying when we achieve something. Our normal emotion of sadness and happiness can become polarized into more severe forms. Sadness can become profound despair or depression and happiness can become elation or mania or hypomania. This polarization is called a 'bipole', with depression at one extreme and mania or hypomania at the other. Depression is defined as morbid sadness and it is the combination of both misery and malaise. Depression appears as common cold in the domains of psychiatry.

Melancholia (extreme depression) is one of the great words of psychiatry that ran from Hippocrates (400 BC). ${ }^{1}$ The main task is now to assess and integrate a rich variety of differing approaches to the understanding and treatment of depressive illness. In some cases a condition where mood is presently low but does not fulfill criteria for depression is known as 'dysthymia'. Depression may come as an 'emotional experience', as a 'symptom of other diseases' and as a separate entity 'syndrome' (Depressive disorders).

Depressive disorder is a complex psychiatric disease consisting of many overlapping conditions. It has many faces and that is why patients present to their doctors in different ways. The many faces of depression are often masked, thus making diagnosis difficult in the primary care setting. Depressive disorder is observed in people from all countries and every culture, affecting both sexes, sparing neither the rich nor the poor, tormenting adult ages, forcing the exit of some through self-destruction and steadfastly maintaining its core clinical features. Depressive disorder is relatively common. The prevalence is between $5-20 \%{ }^{2}$ and higher (double) in women. ${ }^{1}$

It has been mentioned in the history that Abraham Lincoln, the former president of United States of
America, Winston Churchill, the former prime minister of Great Britain, great philosophers Sopen Hayer and John Stuart Mill suffered from depressive disorder. George III of England and in 900 BC Jewish Emperor Saul suffered from manicdepressive psychosis. ${ }^{3}$

The clinical presentations of depressive disorders mostly comprise both psychological and biological (physical) symptomatology. Purely biological symptoms are less. But due to the cultural factors and language constraints, biological features are overemphasized. Moreover, lack of acceptance of purely psychological symptoms by our society or even most of our doctors, biological or physical features are more commonly presented by the patients.

Sleep disturbance, burning sensation, pain, anorexia with loss of weight (sometimes excessive eating followed by weight gain, because eating brings temporary relief from distressing feelings; weight gain is due to both excessive eating and psychomotor retardation), vague gastro-intestinal symptoms, constipation, palpitation, diminished libido and amenorrhea occur frequently. Patients may present pessimistic thoughts, guilt feeling, loss of interest with initiative and energy, weeping (crying spell), monosyllabic speech or even mute and idea of worthlessness. Suicidal feeling or rumination is frequent, but actual attempt is very low in our society due to religious background. Generally depressed patients feel most fatigued when they get up in the morning and gradually improve as the day goes on (diurnal variation of mood). Depressed patients may complain of slow thinking or indecisiveness.

Depressive disorder can be effectively managed by treatment of subclinical hypothyroidism, correction of nutritional deficiency, vitamin supplementation along with antidepressant drugs, cognitive behavior therapy, family or social support and in some cases electroconvulsive therapy. Treatment should be continued for 6-9 months or even more. Illness and 
hospitalization induce mild degree of cognitive dysfunction (pseudo-dementia) especially in the elderly. ${ }^{4}$

Depression is one of the important global health problems. So, World Health Organization (WHO) selected 'Depression: A global crisis', as the theme of the world mental health day of $2012\left(10^{\text {th }}\right.$ October) which indicates the need of orientation and motivation of the people.

\section{Dewan AKM Abdur Rahim}

Professor, Department of Psychiatry

Enam Medical College \& Hospital

Savar, Dhaka.

\section{References}

1. Checkley S. Depression. In: Hill P, Murray R, Thorley A (eds). Essentials of postgraduate psychiatry. $2^{\text {nd }}$ edn. London: Grune \& Stratton, Inco, 1986: 381-403.

2. Green B. Affective disorders. In: Green B (ed). Problem based psychiatry. 1st edn. New Delhi: BI Churchill Livingstone Pvt Ltd, 1996: 47-57.

3. Beniamin K. 11 historical geniuses and the possible mental disorders. Available at: www.mentalfloss.com/../ 141360. Accessed October 2012.

4. Gelder M, Harrison P, Cowen P. Mood disorders. In: Gelder M, Harrison P, Cowen P (eds). Short Oxford textbook of psychiatry. $5^{\text {th }}$ edn. New Delhi: Oxford University Press, 2005: 216-265. 